\title{
Establishment of the Deep-sea Soft Sediments Shearing Strength-Shearing Displacement Model
}

\author{
Hongyun $\mathrm{Wu}$ \\ College of Mechanical and Electrical Engineering \\ Central South University, Changsha 410083, China \\ $\&$ \\ Changsha Institute of Mining Research, Changsha 410012, China \\ Tel: 86-731-88671-485 E-mail: why@cimr.com.cn \\ Jiangsan He \\ College of Mechanical and Electrical Engineering, Central South University \\ Changsha 410083, China \\ Xinming Chen \& Yuqing Gao \\ Changsha Institute of Mining Research, Changsha 410012, China \\ Shaojun Liu \\ College of Mechanical and Electrical Engineering, Central South University \\ Changsha 410083, China
}

The research is financed by the sub-item of the Deep-sea Resource Perambulation Technology of COMRA (No. DYXM-115-04-02-03). (Sponsoring information)

\begin{abstract}
The shearing strength-shearing displacement model of deep-sea soft sediments is very important to predict the traction and slip ratio of nodule collector, and optimize the running mechanism of nodule collector. According to the physical mechanics characters of the deep-sea soft sediments, the 400 sodium molybdate swell soils are selected as the preparation materials of the deep-sea soft sediments, and the demixion preparation method is adopted to simulate the deep-sea soft sediments in the lab, and the shearing test of the rectangle board of $20 \times 50 \mathrm{~cm}$ under different grounding pressures is completed in the soil slot. The test result shows that the simulated deep-sea soft sediments have the representative shearing strength-shearing displacement character of brittle soils. Three shearing strength-shearing displacement models of brittle soils are analyzed in the article, and the shearing strength-shearing displacement model being the same with the deep-sea soft sediments based on maximum shearing strength, residual shearing strength, and elastic modules is established, which can offer theoretical support for the structure optimization of running track and the enhancement of the running performance.
\end{abstract}

Keywords: Deep-sea soft sediments, Shearing strengthen-shearing displacement model, Nodule collector

\section{Introduction}

Wide deep-sea bed contains abundant mental mines which attract many scientists from various countries and regions to study and finally develop and utilize the sea bed mental mine resources. Based on former investigation and exploitation result, China Ocean Mineral Resources Research and Development Association applied the development region of 150 
thousands square kilometers to the National Seabed Authority of China in March of 1991, and at March 5, 1999, completed the confirmation of the mental nodule diggings of 75 thousands kilometers, and established the exploitation technology research plan of multi-mental nodule region, and developed the exploitation technology research of multi-mental nodule region. As the stage research of the multi-mental nodule research plan, the nodule collector (Chen, $2000 \& \mathrm{Li}$, 2001) (made by Changsha Institute of Mining Research) successfully implemented the comprehensive exploitation test on the soft lake bottom of 134m in 2001 (Wang, 2001). In the test, the nodule collector sunk and slid in the original place, which restrained the running performance and passing performance of the nodule collector on the soft lake bottom.

The predict the traction and the slip ratio of the nodule collector on the soft sediments, and enhance its passing performance and running performance, the relationship between the shearing strength and the shearing distortion of soft sediments needs to be known. The function of the rectangle shearing board to shear the soils flatly under normal load is similar with the function of the track vehicles shearing soils, so the level traction of the rectangle shearing board under appointed normal load can be used to establish corresponding shearing strength-shearing displacement model.

Therefore, according to the physical mechanics character of soft sediments in the multi-mental nodule diggings of China, the simulation research of lab deep-sea soft sediments is developed, and the shearing test of simulating deep-sea soft sediments is completed, and the shearing strength-shearing displacement model of soft sediments is established, which can offer theoretical references to predict the traction and the slip ratio of the nodule collector on the soft sediments, optimize the running equipment of the nodule collector and enhance the running performance and the passing performance of the nodule collector.

\section{Rectangle board shearing test}

\subsection{Simulation of deep-sea soft sediments}

The physical mechanics characters of deep-sea soft sediments can be describes as follows. The surface presents flow state, and the flow state, fluidal plastic state, and plastic state change with the increase of depth, and the grain class of over $50 \%$ surface sediments is $0.004 \mathrm{~mm}$ (Song, 1999, P.47-54), and the original position test result of average slip resistance (Gao, 2001, P.425-428) is $1 \sim 7.8 \mathrm{kPa}$ in $0 \sim 30 \mathrm{~cm}$. Therefore, the 400 sodium molybdate swell soils are adopted as the simulated materials of deep-sea soft sediments to prepare the simulated sediments layer lay layer. The physical mechanics characters of simulated deep-sea soft sediments are seen in Table 1, and their main physical mechanics characters are close to the main physical mechanics characters of deep-sea soft sediments, so they can be used to research the shearing strength-shearing displacement model of soft sediments.

\subsection{Test method and equipments}

As seen in Figure 1, under the function of balancing weight, the shearing board sinks to certain depth, and after it is stable, the hydraulic ram tows the pull rod and drives the shearing board to shear levelly and stimulate the sediments, and the shearing test of the shearing board is completed. The change of the grounding pressure is implemented by adjusting the amount of balancing weight.

The piston of the hydraulic ram is connected with the sensor by the whorl, and the sensor connects with flange, and the flange connected with the top end of the pull rod by the bolt to ensure that the pull rod keeps vertically in the traction. The down end of the pull rod connects with the suspension link on the former end of the shearing board by the bold to eliminate the level effect of the piston to the shearing board. The measurement data of sensor is the level traction on the shearing board.

The soil slot in the test has the length of $1.8 \mathrm{~m}$, the width of $0.8 \mathrm{~m}$ and the height of $0.6 \mathrm{~m}$, and both sides adopt transparent toughened glasses, and in the test, the shearing of simulated sediments can be observed, and the height of the laid simulated sediments is $0.5 \mathrm{~m}$.

The rectangle shearing board has the length of $500 \mathrm{~mm}$, the width of $200 \mathrm{~mm}$, and the tooth height of $70 \mathrm{~mm}$ which are equidistantly arranged in 4 teeth.

The sensor is the draught-pressure sensor, and the scale is $10 \mathrm{KN}$, and the measurement precision is $0.05 \%$.

The level shearing speed of the rectangle board is the traction speed of the hydraulic ram, i.e. $1 \mathrm{~cm} / \mathrm{s}$, and the speed keeps constant.

\section{Test result and data analysis}

After the balancing weight is loaded, the shearing board sinks naturally, and after it is stable, the sediments in front of the shearing board are removed to eliminate the influence of the soil resistance. The length and the width of the removed sediments are equal with the length and the width of the shearing board, and the depth is the sinking quantity after loading and stabilizing of the sharing board. The weights of loading balancing weight respectively are $0 \mathrm{~kg}, 25 \mathrm{~kg}$ and $40 \mathrm{~kg}$, and the grounding pressures respectively are $1.0 \mathrm{kPa}, 3.5 \mathrm{kPa}$ and $5.0 \mathrm{kPa}$, and five times of shearing tests are 
made respectively to obtain the average values of the measurement results.

The measurement data obtained in the shearing test indicates the relationship of the traction and the shearing displacement of simulated sediments, and to acquire the relationship between the shearing strength with the shearing displacement, the traction can be converted to the shearing strength of simulated sediments.

$$
\tau=\frac{F}{A}=\frac{F}{L(b+2 h)}
$$

Where, $\mathrm{F}(\mathrm{N})$ is the traction, $\mathrm{A}\left(\mathrm{cm}^{2}\right)$ is the shearing area, $\mathrm{L}(\mathrm{cm})$ is the grounding length, $\mathrm{h}(\mathrm{cm})$ is the track tooth height, and $\mathrm{b}(\mathrm{cm})$ is the grounding width.

To visually obtain the relationship between the change rule of shearing strength with the shearing displacement of sediments, the shearing displacement is the abscissa, and the test data of shearing strength is the longitudinal coordinates, and the relationship curve between the shearing strength and the shearing displacement of sediments under original testing condition is seen in Figure 4, which simulates the curve relationships between the shearing strength measurement average values and the shearing displacement under the grounding pressures of $1.0 \mathrm{kPa}, 3.5 \mathrm{kPa}$ and $5.0 \mathrm{kPa}$.

From Figure 4, the change of the shearing strength of soft sediments is consistent with the change of shearing displacement, i.e. the shearing strength of soft sediments increases quickly with the increase of shearing displacement, and quickly descends when achieving the peak value, and slowly reduces to stable residual shearing strength.

According to Figure 4, under the grounding pressures of $1.1 \mathrm{kPa}, 3.5 \mathrm{kPa}$ and $5.0 \mathrm{kPa}$, the shearing strengths of soft sediments all achieve the peak values (respectively $1.21 \mathrm{kPa}, 1.46 \mathrm{kPa}$ and $1.68 \mathrm{kPa}$ ), and the corresponding shearing displacement is $3.6 \mathrm{~cm}$, and their residual shearing strengths respectively are $0.5 \mathrm{kPa}, 0.85 \mathrm{kPa}$ and $1.1 \mathrm{kPa}$.

\section{Shearing strength-shearing displacement model of soft sediments}

\subsection{Shearing strength-shearing displacement model of brittle soils}

In the classic earth pressure theories, two usual representative soils are plastic soils and brittle soils, and both character curves of shearing strength-shearing displacement respectively are seen in the curve A and the curve B in Figure 5. In Figure 5, the curve $\mathrm{A}$ is a smooth shearing strength-shearing displacement curve, and the shearing strength slowly achieves to the maximum shearing strength $\tau_{\max }$ and the change of shearing strength is small, and the whole curve has no obvious "hump". In the curve B, the "hump" of the maximum shearing strength $\tau_{\max }$ occurs, and it possesses significant stable stage of residual shearing strength after yielding limitation.

In the measurement data curve of Figure 4, the relationship between shearing strength and shearing displacement of soft sediments has representative character of brittle soils.

Aiming at the mechanical character of brittle soils, Bekker (Bekker, 1956), Wong JY (Wong, 1989), Schwarz (E. Schulte, 200, P.121-131) and Sup Hong (Jong-su Choi, 2003, P.139-143) put forward different shearing strength-shearing displacement models.

Bekker's shearing strength-shearing displacement model can be denoted by an equation similar with damp librations.

$$
\tau=\frac{(c+\sigma \tan \phi)}{y_{\max }}\left\{\exp \left(-K_{2}+\sqrt{K_{2}^{2}-1}\right) K_{1} j-\exp \left(-K_{2}+\sqrt{K_{2}^{2}-1}\right) K_{1} j\right\}
$$

Where, $\mathrm{j}(\mathrm{cm})$ is the shearing displacement of soils, $\varphi\left(^{\circ}\right)$ is the interior friction angle of soils, $K_{2}$ and $K_{l}$ are coefficients, $y_{\max }$ is the maximum value of the function in the brackets, $\mathrm{c}(\mathrm{kPa})$ is the cohesion of soils, and $\sigma(\mathrm{kPa})$ is the grounding pressure.

Wong JY established the shearing strength-shearing displacement model of soft soils.

$\tau=\frac{\tau_{m}}{E}\left[1+\left(\frac{E}{1-e^{-1}}-1\right) e^{1-j / k_{w}}\right]\left(1-e^{1-j / k_{w}}\right)$

Where, $\mathrm{E}$ is the sensitive coefficient of soils, $\mathrm{k}_{\mathrm{w}}(\mathrm{cm})$ is the elastic module, i.e. the corresponding shearing displacement of the maximum shearing strength.

Schwarz et al established the shearing strength-shearing displacement model of swell soils.

$\tau(s)=\left[\tau_{\max } \cdot e^{-b(s-\Delta s)}+\tau_{\operatorname{Rest}}\right] \times\left[\frac{1}{1+f e^{-d s}}\right]$

Where, $\tau_{\max }(\mathrm{kPa})$ is the maximum shearing strength of soils, $\tau_{\text {rest }}(\mathrm{kPa})$ is the residual shearing strength of soils, $\mathrm{b}$ is the fading exponent, $\Delta \mathrm{s}(\mathrm{cm})$ is the displacement offset, $\mathrm{f}$ and $\mathrm{d}$ are Soil fracture parameters, which are respectively the 
fracture factor and the fracture exponent.

Sup Hong established the shearing strength-shearing displacement model of swell similar with Huang ZY's model.

\subsection{Establishment of soft sediments shearing-strength-shearing displacement model}

Bekker's model and Wong's model mainly aim at the soils of earth, and they may not suit for the soft sediments with flow surface and high water content. Bekker's model is complex and the computation is fussy. Wong's model defines the relationship between the maxim shearing strength and the residual shearing strength as the sensitive coefficient of soils, which is too qualitative. Schwar's model firstly introduces the residual shearing strength, and adopt the attenuation index, the destroying coefficient, and the destroying index to represent the influences of the track structure parameters, but the whole model with more parameters and influencing factors is too complex.

According to Figure 4, the shearing strength of soft sediments quickly increases with the increase of shearing displacement, and different peak values can not be achieved at same shearing displacement, and the shearing strength quickly descends to corresponding stable value of residual shearing strength. In this way, the shearing stress of soft sediments is related with the maximum shearing strength, the residual shearing strength and the shearing elastic module, but they are independent each other. Therefore, it is not difficult to establish the shearing strength-shearing displacement model of soft sediments which takes the maximum shearing stress, the residual shearing strength, and the shearing elastic module as the characters of inflexion, and takes $e^{1-j / k_{m}}$ and $e^{-j / k_{m}}$ as the change characters. The concrete relationship is seen in the formula as follows.

$$
\tau(j)=\left[\tau_{\max } \cdot e^{1-j / k_{m}} \cdot e /(e-1)+\tau_{\operatorname{Re} s t} \cdot\left(1-e^{1-j / k_{m}}\right)\right]\left(1-e^{-j / k_{m}}\right)
$$

Where, $k_{m}(\mathrm{~cm})$ is the corresponding shearing displacement of the maximum shearing strength.

The advantage of this model is that only the measurement values of parameters including the maximum shearing strength, the residual shearing strength, and the shearing elastic module of the shearing board in the shearing test with appointed grounding pressure are confirmed, the corresponding shearing strength-shearing displacement model can be established, and the shearing strength-shearing displacement model of soft sediments can be simplified largely.

According to the measurement data in Figure 4, under the grounding pressures of $1.1 \mathrm{kPa}, 3.5 \mathrm{kPa}$ and $5.0 \mathrm{kPa}$, the relationships between the shearing strength and the shearing displacement of soft sediments respectively are

$$
\begin{aligned}
& \tau(j)=\left[1.04 \times\left(1-e^{1-j / 3.6}\right)+0.5\right]\left(1-e^{-j / 3.6}\right) \\
& \tau(j)=\left[1.38 \times\left(1-e^{1-j / 3.6}\right)+0.85\right]\left(1-e^{-j / 3.6}\right) \\
& \tau(j)=\left[1.49 \times\left(1-e^{1-j / 3.6}\right)+1.1\right]\left(1-e^{-j / 3.6}\right)
\end{aligned}
$$

The formula (6), the formula (7) and the formula (8) are simplified largely comparing with the formula (5), which can help to predict, analyze and solve the tractions of vehicle.

\subsection{Validation of model}

To validate the correctness of the model, the measurement data of shearing strength-shearing displacement under the grounding pressures of $1.0 \mathrm{kPa}, 3.5 \mathrm{kPa}$ and $5.0 \mathrm{kPa}$ are fitted by the formula (5), and the fitting result is seen in Figure 6 , and relative coefficients respectively are $0.76,0.78$ and 0.75 , which indicates that the model accords with the change rule of shearing strength of soft sediments with the change of shearing displacement.

\section{Conclusions}

(1) The soft sediments have representative characters about shearing strength and shearing displacement of brittle soils, i.e. the shearing strength of soft sediments quickly increases with the increase of shearing displacement, and different peak values can not be achieved at same shearing displacement, and the shearing strength quickly descends to corresponding stable value of residual shearing strength.

(2) According to the measurement values of parameters including the maximum shearing strength, the residual shearing strength, and the shearing elastic module of the shearing board in the shearing test with appointed grounding pressure, the corresponding shearing strength-shearing displacement model can be established as follows.

$$
\tau(j)=\left[\tau_{\max } \cdot e^{1-j / k_{m}} \cdot e /(e-1)+\tau_{\operatorname{Re} s t} \cdot\left(1-e^{1-j / k_{m}}\right)\right]\left(1-e^{-j / k_{m}}\right)
$$

(3) The fitting result of the shearing strength-shearing displacement model indicates that this model can be applied for the prediction and solving of the traction of the nodule collector on deep-sea soft sediments. 


\section{References}

Bekker, MG. (1956). Theory of Land Locomotion. The University of Michigan Press, Library of Congress Card Number 56-10101.

Chen, Xinming. (2000). Technology design of the pilot mining seabed tracked vehicle. Changsha: Changsha Institute of Mining Research.

E. Schulte, R. Handschuh, W. Schwarz. (2003). Transferability of Soil Mechanical Parameters to Traction Potential Calculation of a Tracked Vehicle. The Proceedings of the Fifth ISOPE Ocean Mining Symposium. Tsukuba, Japan. P.121-131.

Gao, Yuqing. (2001). Research and development of in-situ test system of the characteristics of physical mechanics of seabed soft sediments. Conference on China ocean Resource Research and Development Association. Beijing: COMRA. P.425-428.

Jong-su Choi, Sup Hong \& Hyuang-Woo Kim. (2003). An Experimental Study on Tractive Performance of Tracked Vehicle on Cohesive Soft Soil. The Proceedings of the Fifth ISOPE Ocean Mining Symposium. Tsukuba, Japan. P.139-143.

Li, Li. (2001). Development of self-propelled seabed tracked vehicle. Changsha: Changsha Institute of Mining Research.

Song, Lianqing. (1999). The physical properties of surface sediments in oceanic polymetallic nodule. Acta Oceanologica Sinica. No.6(21). P.47-54.

Wang, MH. (2001). Research Report of Lake Test of the Pilot-testing Mining System. China ocean Resource Research and Development Association (COMR R\&D). P.71-72.

Wong, JY. (1989). Terramechanics and Off-Road Vehicles, Elsevier Science Publishers B. V., Amsterdam.

Wu, Hongyun, Chen Xinming \& Gao Yuqing. (2006). The New Principle of In-situ Testing Shearing Strength of Marine Sediment. Mining and Processing Equipment. No.12. P.16-17.

Table 1. Physical mechanics characters of simulating deep-sea soft sediments

\begin{tabular}{|c|c|c|c|c|}
\hline Depth $(\mathrm{cm})$ & $\begin{array}{c}\text { Water ratio } \\
\mathrm{W}(\%)\end{array}$ & $\begin{array}{c}\text { Soil particle } \\
\text { density } \rho_{\mathrm{s}} \\
\left(\mathrm{kN} / \mathrm{m}^{2}\right)\end{array}$ & $\begin{array}{c}\text { Natural density } \\
\mathrm{P}\left(\mathrm{kN} / \mathrm{m}^{2}\right)\end{array}$ & $\begin{array}{c}\text { Slip resistance } \\
(\mathrm{kPa})(\mathrm{Wu}, 2006, \\
\mathrm{P} .16-17)\end{array}$ \\
\hline $0 \sim 10$ & 101.8 & 12.6 & 10.9 & 1.3 \\
\hline $10 \sim 20$ & 98.1 & 12.1 & 10.9 & 4.2 \\
\hline $20 \sim 30$ & 81.3 & 11.4 & 10.9 & 7.6 \\
\hline
\end{tabular}

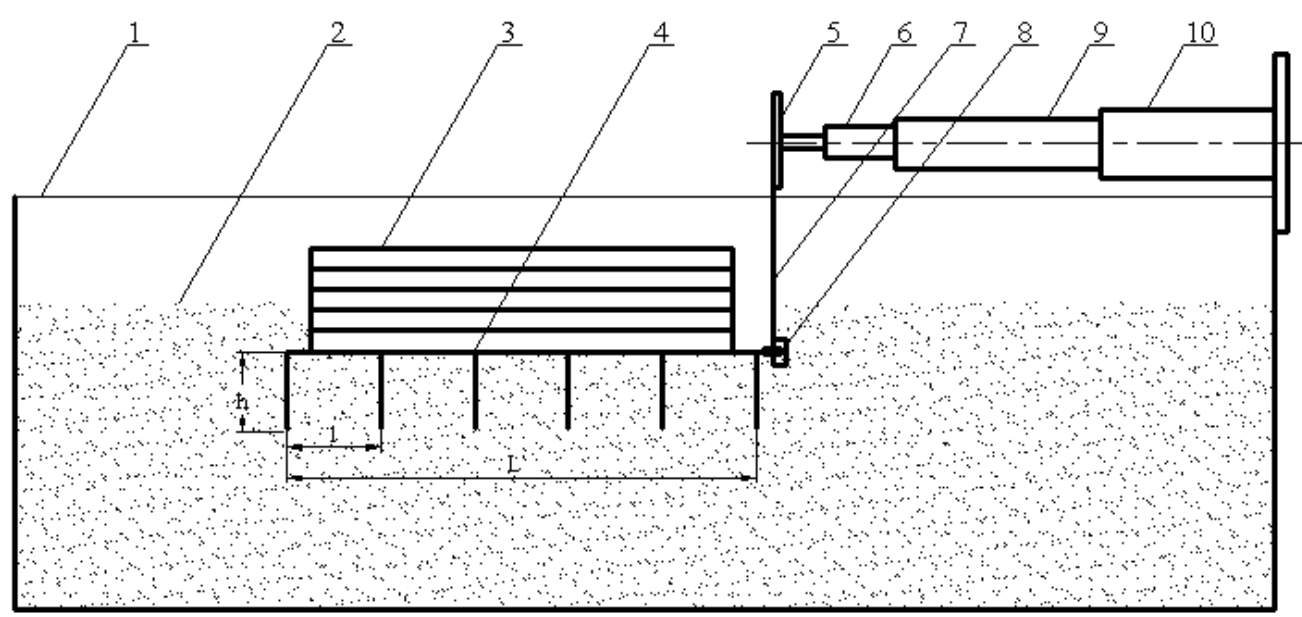

Figure 1. Principle Chart of Shearing Test (1-soil slot, 2-simulated sediments, 3-balancing weight, 4-shearing board, 5-flange, 6-sensor, 7-pull rod, 8-suspension link, 10-hydraulic ram) 


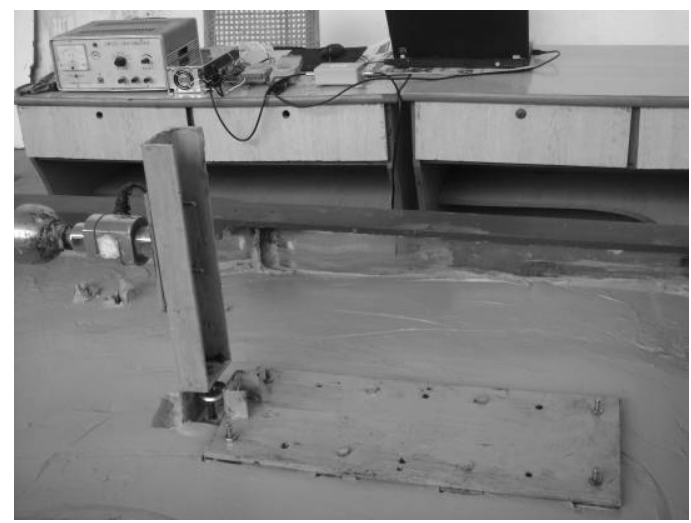

Figure 2. Practical Principle Chart of Shearing Test

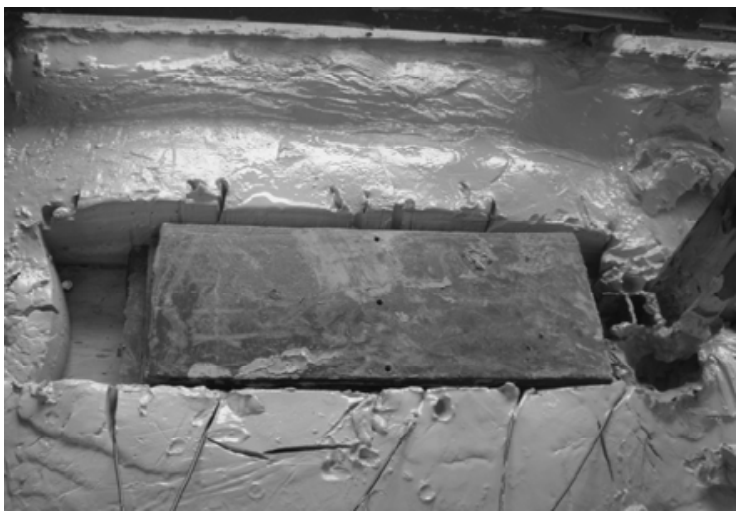

Figure 3. Loading Shearing Test

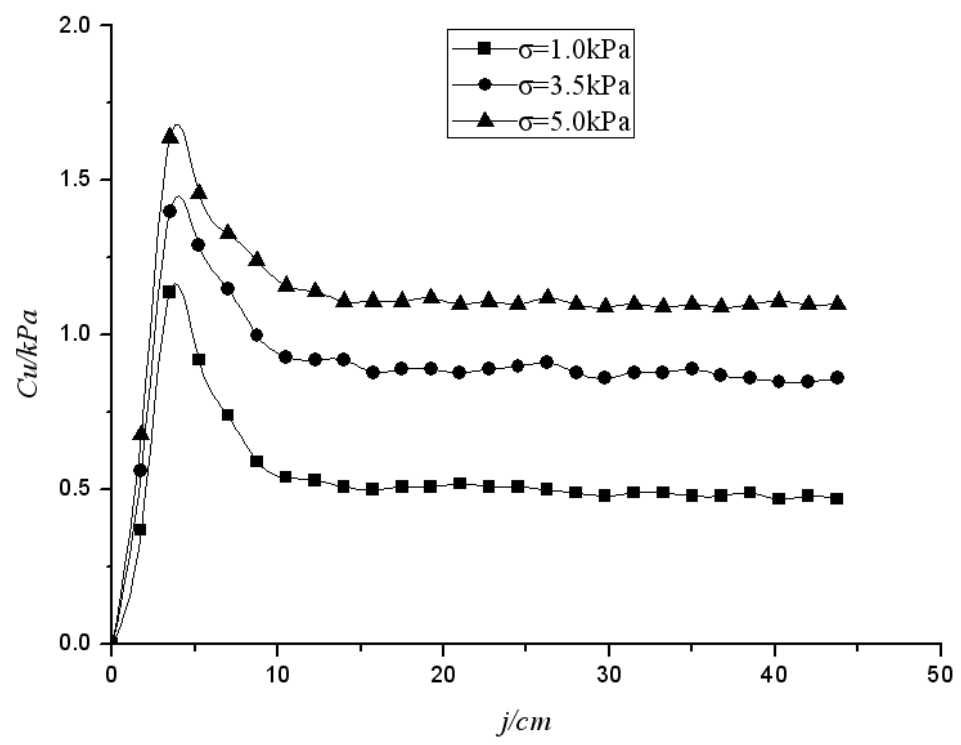

Figure 4. Shearing Test Curve of $50 \times 20 \mathrm{~cm}$ Shearing Board 


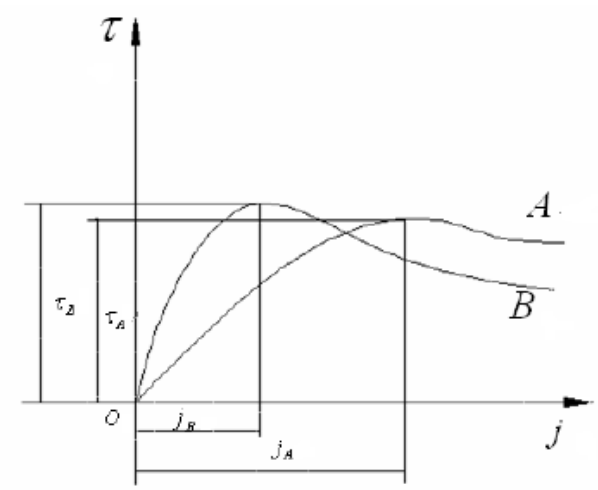

Figure 5. Shearing Strength-Shearing Displacement Curve of Representative Soils

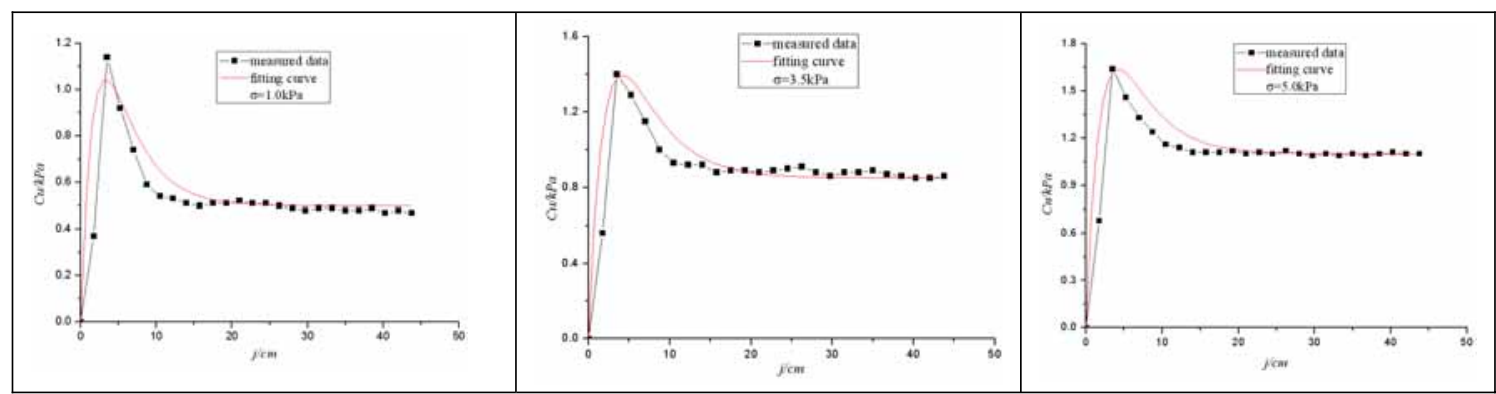

Figure 6. Curve Fitting Validation of Shearing Strength-Shearing Displacement Measurement Data 